\title{
ANÁLISE IMUNOCITOQUÍMICA DO INFILTRADO INFLAMATÓRIO NA MIOSITE COM CORPOS DE INCLUSÃO CITOPLASMÁTICA E EM OUTRAS DOENÇAS NEUROMUSCULARES COM VACÚOLOS MARGINADOS
}

\author{
ROSANA HERMINIA SCOLA*, LINEU CESAR WERNECK**, FÁBIO MASSAITI IWAMOTO***, \\ IARA TABORDA DE MESSIAS ${ }^{* * *}$, LUINE VIDAL TSUCHIYA*****
}

\begin{abstract}
RESUMO - Encontramos 16 casos com vacúolos marginados entre 1400 biópsias musculares cujo diagnóstico final foi miosite com corpos de inclusão citoplasmática esporádica (MCIC) (4 casos), atrofia muscular espinhal juvenil ( 6 casos), miopatias distais ( 3 casos), distrofia das cinturas pélvica e escapular ( 2 casos) e neuropatia periférica (1 caso). Foram utilizados anticorpos monoclonais contra linfócitos $\mathrm{T}$ totais e subpopulações (CD4+ e CD8+), linfócitos B, macrófagos, células exterminadoras naturais (NK), imunoglobulinas e porção C3 do complemento. A análise foi quantitativa e de acordo com o local de acúmulo (interstício, intra-fibra e perivascular). Linfócitos CD8+ foram encontrados no interstício na maioria dos casos, sendo menos comuns dentro das fibras musculares e raros no espaço perivascular. Os casos de MCIC apresentaram maior número de linfócitos CD8+ se comparados às outras doenças. A proporção de células $\mathrm{CD} 8+/ \mathrm{CD} 4+$ foi maior na $\mathrm{MCIC}$ do que nas outras doenças. Existiam macrófagos em grande proporção na MCIC, miopatias distais e em um dos casos de distrofia das cinturas pélvica e escapular. Células NK foram frequentes no interstício nos casos de MCIC e mais raras nas outras doenças. Houve maior depósito de imunoglobulinas e complemento nos casos de MCIC do que nas demais doenças. O grande número de células $\mathrm{CD} 8+$ e a relação $\mathrm{CD} 8+/ \mathrm{CD} 4+$ podem auxiliar no diagnóstico diferencial da MCIC de outras doenças neuromusculares com vacúolos marginados.
\end{abstract}

PALAVRAS-CHAVE: imunocitoquímica, vacúolos marginados, inclusão citoplasmática, miosite com corpos de inclusão citoplasmática, atrofia muscular espinhal juvenil, miopatias distais, distrofia muscular das cinturas pélvica e escapular.

\section{Immunocytochemical analysis of the inflammatory infiltrate in inclusion body myositis and other neuromuscular disorders with rimmed vacuoles}

ABSTRACT - Among 1400 muscle biopsies, we found 16 cases with rimmed vacuoles whose diagnosis were sporadic inclusion body myositis (IBM) (4 cases), juvenile spinal muscular atrophy (6 cases), distal myopathies ( 3 cases), limb-girdle muscular dystrophy ( 2 cases), and peripheral neuropathy ( 1 case). Monoclonal antibodies reactive for T lymphocytes and subsets, B lymphocytes, macrophages, natural killer cells, immunoglobulins, and complement were used to analyze the inflammatory infiltrate. The analysis was quantitative and according to the site of accumulation (interstitial, endomysial, and perivascular). The immunocytochemical analysis showed CD8+ lymphocytes in the interstitial in most cases, occasionally inside of muscle fibers, and rarely in the perivascular region. The IBM cases had an increased number of CD8+ lymphocytes comparing with the other diseases. $\mathrm{CD} 8+/ \mathrm{CD} 4+$ ratio was increased in IBM compared with the other diseases. Macrophages were frequent in IBM, distal myopathy, and one case of limb-girdle muscular dystrophy. Natural killer cells were frequent at interstitial

Serviço de Doenças Neuromusculares da Especialidade de Neurologia do Departamento de Clínica Médica do Hospital de Clínicas da Universidade Federal do Paraná (UFPR): *Professora Assistente; **Professor Titular; ***Estudante de Medicina, Bolsista de Iniciação Científica (CNPq/UFPR); *****orofessora Adjunta; ******Boquímica. Aceite: 7-abril-1998.

Dra. Rosana Herminia Scola - Serviço de Doenças Neuromusculares, Hospital de Clínicas, UFPR - Rua General Carneiro 181, $3^{\circ}$ andar - 80060-900 Curitiba PR, Brasil. E-mail: scola@ hc.ufpr.br 
site in IBM but rare in the other diseases. Immunoglobulins and complement deposition were slightly more intense in IBM than in the other diseases. The case of peripheral neuropathy had no cells or immunoglobulins deposition. The increased number of CD8+ lymphocytes and the CD8+/CD4+ ratio help to distinguish IBM from other neuromuscular disorders with rimmed vacuoles.

KEY WORDS: immunocytochemistry, rimmed vacuoles, cytoplasmic inclusion, inclusion body myositis, juvenile spinal muscular atrophy, distal myopathies, limb-girdle muscular dystrophy.

A miosite com corpos de inclusão citoplasmática (MCIC) é uma miopatia inflamatória crônica cujo diagnóstico baseia-se principalmente no achado de vacúolos marginados na biópsia muscular ${ }^{1-3}$. No entanto, grande número de doenças neuromusculares também podem apresentar esses tipos de vacúolos, histologicamente denominados corpos de inclusão citoplasmática. O achado de vacúolos marginados tem sido descrito na distrofia oculofaringéia, músculos desinervados, miopatias distais, distrofia das cinturas, miopatias congênitas e mais raramente em outras doenças ${ }^{4-8}$. Análises imunocitoquímicas demonstraram que linfócitos T citotóxicos (CD8+) e macrófagos predominam na biópsia muscular de pacientes com $\mathrm{MCIC}^{9-11}$, mas o infiltrado inflamatório nas outras doenças neuromusculares com vacúolos marginados foi pouco estudado ${ }^{12}$.

Realizamos a análise imunocitoquímica dos casos que apresentavam vacúolos marginados sugestivos de corpos de inclusão citoplasmática na biópsia muscular com os objetivos de (1) estudar as subpopulações de linfócitos, macrófagos, células exterminadoras naturais e a deposição de complemento e imunoglobulinas na biópsia muscular desses pacientes e (2) comparar os achados na MCIC com os de outras doenças neuromusculares com vacúolos marginados.

\section{CASUÍSTICA E MÉTODOS}

Foram detectados 16 casos, entre 1400 biópsias musculares realizadas no Serviço de Doenças Neuromusculares do Hospital de Clínicas da UFPR entre 1976 e 1990, em que a presença de vacúolos na histologia sugeria corpos de inclusão citoplasmática. Foram considerados corpos de inclusão citoplasmática os vacúolos marginados que apresentavam reação positiva na fosfatase ácida na periferia ou centro, contendo produtos de degradação citoplasmática e ou estruturas filamentares na microscopia eletrônica ${ }^{8}$ (Figs 1 e 2). A idade dos pacientes variou entre 7 e 69 anos, com média de idade de 36 anos. Doze eram do sexo masculino e quatro do sexo feminino. A idade do início da doença variou entre 2 e 59 anos, ocorrendo em média aos 20,5 anos e o tempo de doença entre 2 e 45 anos, com média de 5,5 anos (Tabela 1).

De acordo com as características clínicas, laboratoriais, neurofisiológicas e histológicas já previamente relatadas $^{8}$, encontraram-se os seguintes diagnósticos: miosite com corpos de inclusão citoplasmática em quatro pacientes (Casos 1, 2, 3, 4); atrofia muscular espinhal juvenil em seis pacientes (Casos 5, 6, 7, 8, 9, 10); miopatias distais em três pacientes (Casos 11, 12,13); distrofia muscular de cinturas pélvica e escapular em dois pacientes (Casos 14, 15); neuropatia periférica de etiologia não determinada em um paciente (Caso 16).

As biópsias musculares foram processadas através de técnicas a fresco e histoquímica sendo coradas com hematoxilina-eosina, tricromo de Gomori modificado, oil red O, PAS, cresil violeta, ATPase pH 9,4, 4,3 e 4,6, NADH-tetrazolium redutase, miofosforilase, esterase não-específica, desidrogenase succínica, citocromo-c-oxidase e fosfatases alcalina e ácida. $\mathrm{O}$ diagnóstico anatomopatológico foi miopatia (ativa e/ou crônica) em cinco casos, mista (miopatia e desinervação) em sete, desinervação em dois e miopatia inflamatória em dois casos, conforme critérios estabelecidos anteriormente ${ }^{13,14}$.

As biópsias foram posteriormente armazenadas em nitrogênio líquido a $-170^{\circ} \mathrm{C}$ até serem utilizadas para estudo imunocitoquímico. Cortes histológicos de $4 \mu \mathrm{m}$ foram incubados com anticorpos monoclonais correspondentes a fim de identificar linfócitos T totais (CD11+), linfócito T supressor/citotóxico (CD8+), linfócito $\mathrm{T}$ auxiliar (CD4+), linfócito $\mathrm{B}$, macrófago, complemento $\mathrm{C} 3$, células exterminadoras naturais $(\mathrm{NK})$ e imunoglobulinas A (IgA), G (IgG) e M (IgM). Os anticorpos contra imunoglobulinas e porção C3 do complemento foram obtidos da Behringwerk AG (Malburg, Alemanha) e os demais foram adquiridos da DAKO Corp. (Santa Barbara, Califórnia, USA). Em seguida as secções foram lavadas com tampão salino fosfato (pH 7,4) e incubadas com conjugado anti-espécie polivalente marcado com isotiocianato de fluoresceína. Na sequência as secções foram novamente lavadas com tampão salino fosfato $(\mathrm{pH} 7,4)$ e observadas ao microscópio com luz ultravioleta 


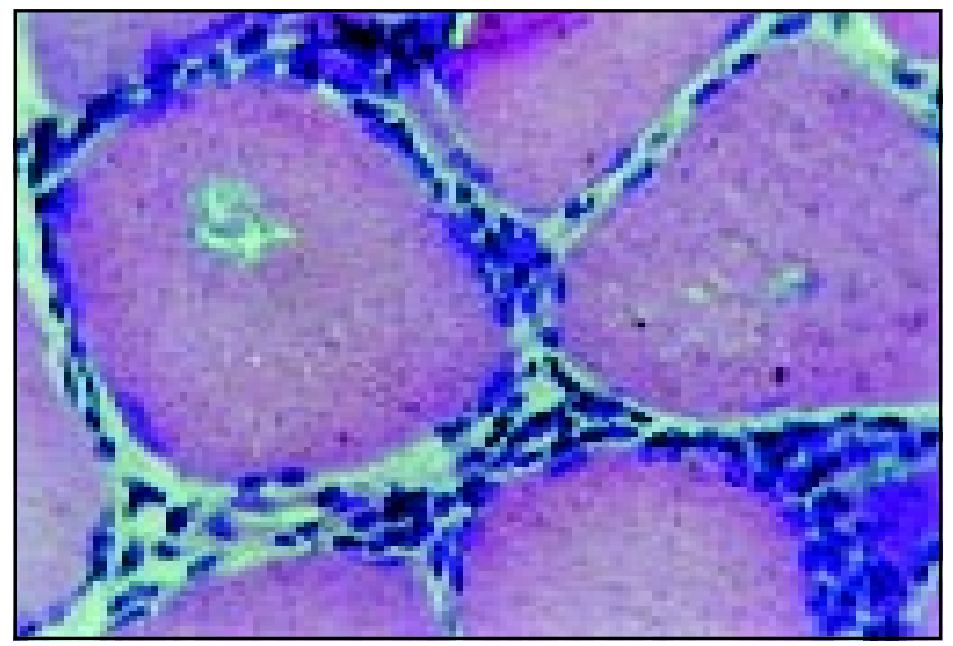

Fig 1. Infiltrado inflamatório intersticial com vacúolo em fibra marginal. Hematoxilina-eosina. 478x. MCIC (Caso 3).

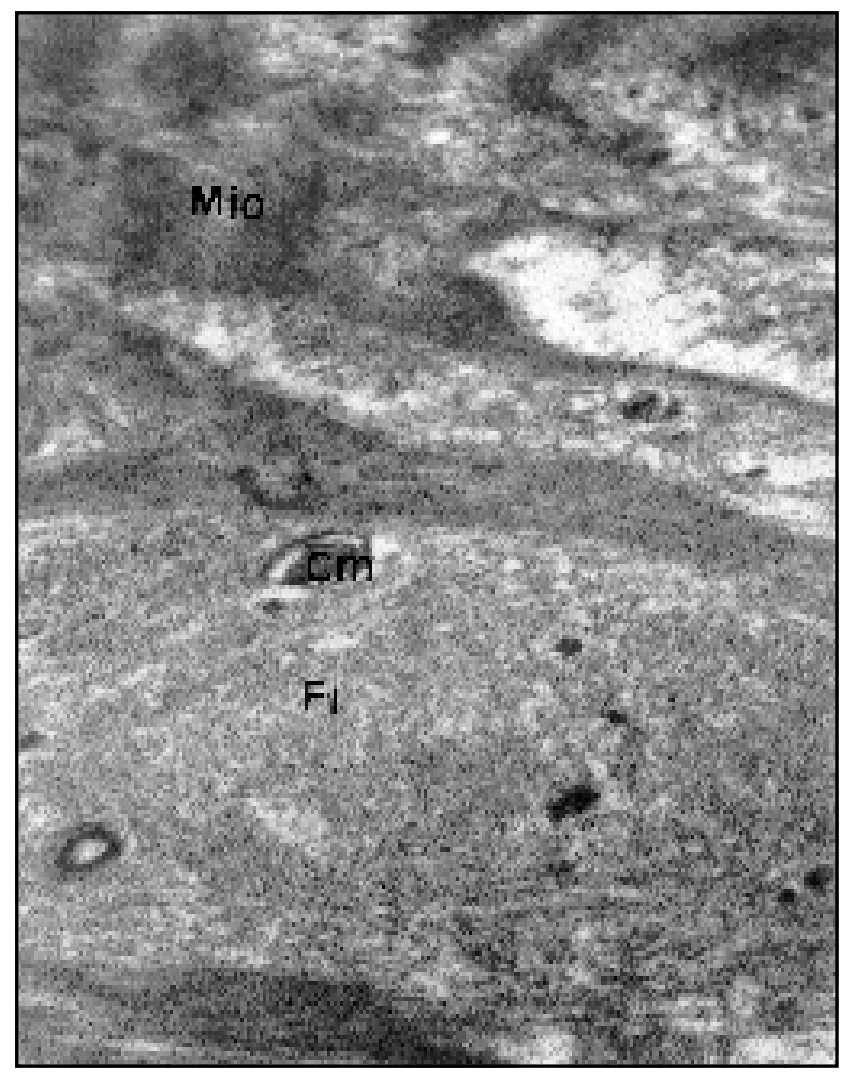

Fig. 2. Filamentos entre miofibrilas e corpos mielínicos. Fi, filamentos; Cm, corpos mielínicos, Mio, miofibrilas. Microscopia eletrônica. 16100x. MCIC (Caso 4). 


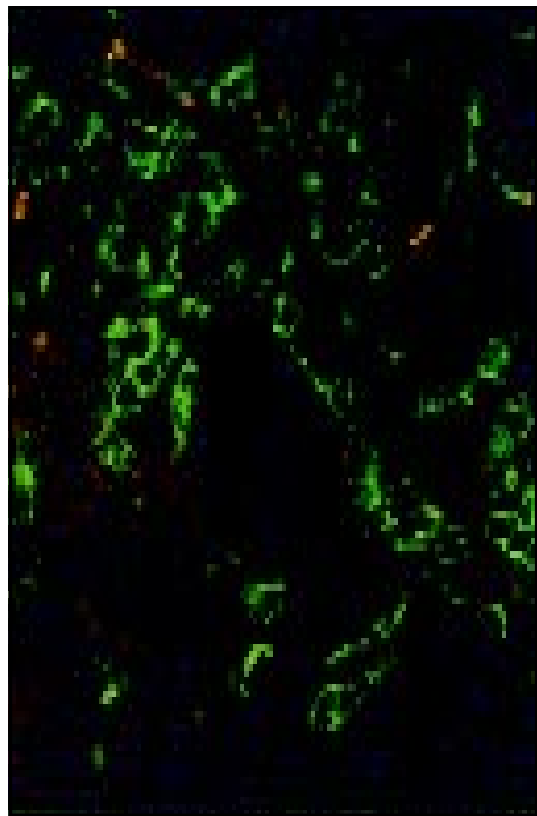

Fig 3. Linfócitos $C D 11+$ no interstício e invadindo fibras. Imuno-histoquímica para CD11+. 885x. MCIC (Caso 3).

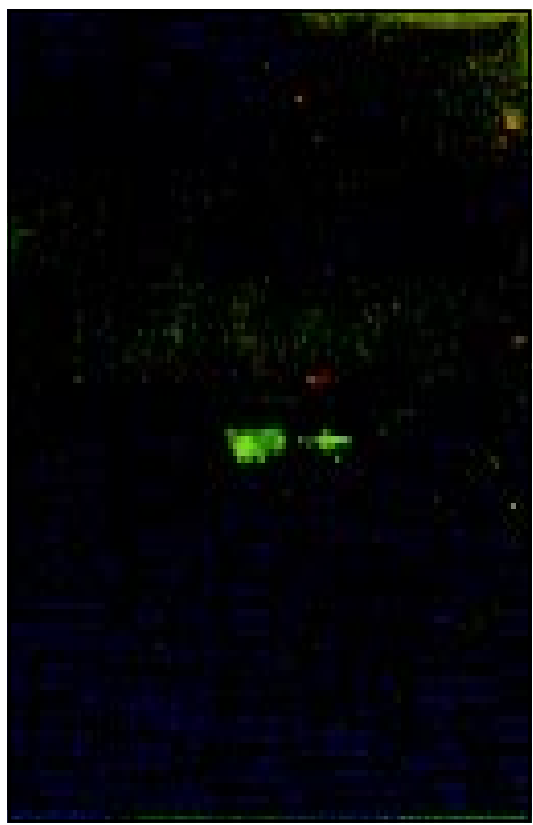

Fig 5. Raros linfócitos CD4+ entre fibras musculares em corte longitudinal. Imuno-histoquímica para CD4+. 885x. MCIC (Caso 3).

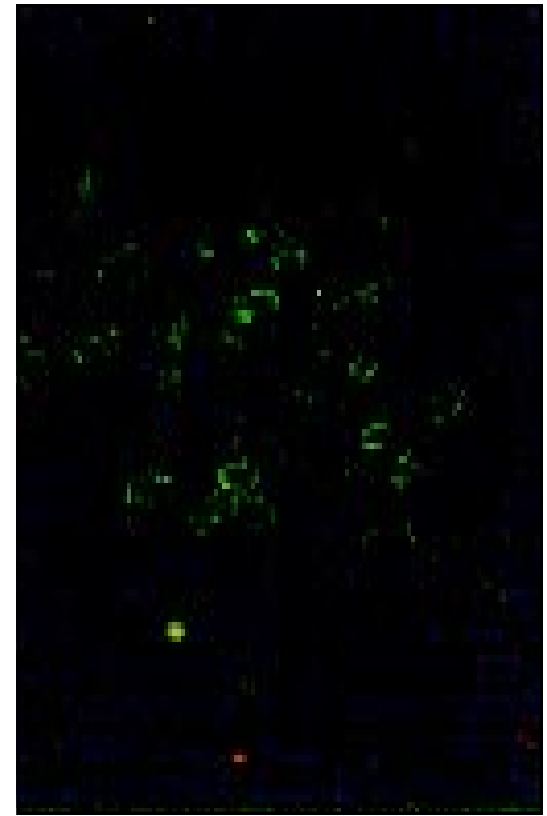

Fig. 4. Inúmeros linfócitos CD8+ no interstício e invadindo fibra necrótica. Imuno-histoquímica para CD8+. 885x. MCIC (Caso 4).

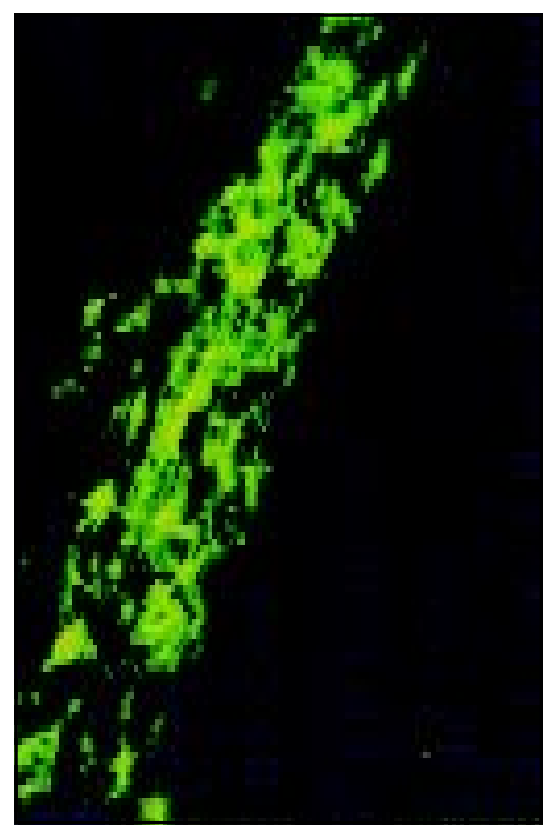

Fig 6. Inúmeros macrófagos no interstício. Imuno-histoquímica para macrófagos. $885 x$. Atrofia muscular espinhal juvenil (Caso 7). 
Tabela 1. Diagnóstico final de pacientes com vacúolos marginados sugestivos de corpos de inclusão.

\begin{tabular}{ccccl}
\hline Caso & Sexo & Idade & Início dos sintomas & Diagnóstico final \\
\hline 1 & M & 28 & 26 & MCIC \\
2 & M & 53 & 43 & MCIC \\
3 & M & 62 & 56 & MCIC \\
4 & F & 71 & 59 & MCIC \\
5 & M & 7 & 5 & Atrofia muscular espinhal juvenil \\
6 & F & 14 & 4 & Atrofia muscular espinhal juvenil \\
7 & M & 16 & 14 & Atrofia muscular espinhal juvenil \\
8 & M & 20 & 18 & Atrofia muscular espinhal juvenil \\
9 & M & 31 & 28 & Atrofia muscular espinhal juvenil \\
10 & F & 69 & 64 & Atrofia muscular espinhal juvenil \\
11 & M & 20 & 15 & Miopatia distal \\
12 & M & 25 & 23 & Miopatia distal \\
13 & M & 47 & 2 & Miopatia distal \\
14 & M & 44 & 15 & Distrofia muscular de cinturas \\
15 & F & 29 & 43 & Distrofia muscular de cinturas \\
16 & M & 41 & 27 & Neuropatia periférica \\
\hline
\end{tabular}

M, masculino; F, feminino; MCIC, miosite com corpos de inclusão citoplasmática. A idade e o início dos sintomas estão expressos em anos.

e epi-iluminação. Para quantificação dos linfócitos e subtipos foram contadas todas as células das secções e aferida a área da biópsia. Foi avaliada em média uma área de $38,5 \mathrm{~mm}^{2}$ de biópsia muscular de cada paciente. A infiltração de macrófagos, células NK, imunoglobulinas e porção C3 do complemento foi classificada de acordo com a intensidade em: 0 = ausente; $1=$ discreto ou raro; $2=$ ocasional ou moderado; $3=$ frequente ou abundante.

\section{RESULTADOS}

Nos casos de MCIC o processo inflamatório foi predominante no interstício, sendo menos marcante no interior das fibras e espaço perivascular (Fig 3). Na MCIC houve predomínio de linfócitos CD8+ com média geral de 17,71 células por $\mathrm{mm}^{2}$ no interstício, 3,63 nas fibras e 0,19 nas áreas perivasculares (Fig 4). A presença de células CD4+ também foi predominante nos casos de MCIC, sendo que no interstício o índice foi de 4,51 células por $\mathrm{mm}^{2}, 0,51$ intra-fibras e 0,01 nos espaços perivasculares (Fig. 5). As células B foram observadas raramente, tendo índice de 0,93 no interstício e não foram vistas nas fibras e nos espaços perivasculares (Tabela 2).

Nas outras doenças observaram-se índices de células inflamatórias menores que os encontrados na MCIC, porém persistindo o predomínio de células CD8+. Houve praticamente ausência de células B e na neuropatia periférica não foi encontrado qualquer tipo de célula (Tabela 2).

Existiam macrófagos em grande proporção na MCIC, miopatias distais e em um dos casos de distrofia muscular de cinturas. Nesses casos, os macrófagos estavam predominantemente no interstício, em torno de fibras necróticas ou nas regiões perivasculares. Nas atrofias espinhais e no outro caso de distrofia muscular das cinturas foi observado mais no interstício (Fig. 6). As células exterminadoras naturais foram observadas no interstício da maioria dos casos de MCIC e mais raramente nos casos de atrofia espinhal, miopatia distal e distrofia muscular de cinturas (Tabela 3).

A relação de células CD8+/CD4+ foi maior na região perivascular e em torno de fibras necróticas que no interstício das fibras nos casos de miosite com corpos de inclusão citoplasmática. Nas demais entidades patológicas, a relação de células CD8+/CD4+ foi maior nas regiões perivasculares e interstício nas distrofias musculares de cinturas (Tabela 4). A relação de células CD8+/CD4+ foi maior nos casos de MCIC do que nas outras doenças com vacúolos marginados. 
Tabela 2. Análise quantitativa de linfócitos em doenças neuromusculares com vacúolos marginados.

\begin{tabular}{|c|c|c|c|c|c|c|c|c|c|c|c|c|}
\hline \multirow[b]{2}{*}{ Doença } & \multicolumn{3}{|c|}{$\mathrm{CD} 8+$} & \multicolumn{3}{|c|}{ CD4+ } & \multicolumn{3}{|c|}{ CD11+ } & \multicolumn{3}{|c|}{ B } \\
\hline & IT & IF & PV & IT & IF & PV & IT & IF & $\mathrm{PV}$ & IT & IF & PV \\
\hline $\operatorname{MCIC}(n=4)$ & 17,71 & 3,63 & 0,19 & 4,51 & 0,51 & 0,01 & 46,84 & 17,55 & 0,45 & 0,93 & 0,00 & 0,00 \\
\hline $\begin{array}{l}\text { Atrofia espinhal } \\
\text { juvenil }(n=6)\end{array}$ & 1,31 & 0,13 & 0,00 & 0,64 & 0,06 & 0,00 & 3,14 & 0,07 & 0,00 & 0,00 & 0,00 & 0,00 \\
\hline $\begin{array}{l}\text { Miopatia } \\
\text { distal }(n=3)\end{array}$ & 0,28 & 0,10 & 0,01 & 0,00 & 0,00 & 0,00 & 1,00 & 0,08 & 0,00 & 0,15 & 0,00 & 0,00 \\
\hline $\begin{array}{l}\text { Distrofia de } \\
\text { cinturas }(n=2)\end{array}$ & 2,16 & 0,22 & 0,07 & 1,05 & 0,75 & 0,01 & 0,32 & 0,00 & 0,00 & 0,00 & 0,00 & 0,00 \\
\hline $\begin{array}{l}\text { Neuropatia } \\
\text { periférica }(n=1)\end{array}$ & 0,00 & 0,00 & 0,00 & 0,00 & 0,00 & 0,00 & 0,00 & 0,00 & 0,00 & 0,00 & 0,00 & 0,00 \\
\hline
\end{tabular}

IT, interstício; IF, intra-fibra; PV, perivascular; MCIC, miosite com corpos de inclusão citoplasmática. Os valores estão expressos em número de células por $\mathrm{mm}^{2}$.

A presença de $\mathrm{C} 3$ e imunoglobulinas foi observada principalmente na MCIC e atrofia espinhal juvenil, sendo menor nas miopatias distais. Não foi observada na neuropatia periférica e distrofia muscular de cinturas pélvica e escapular. Apesar do pequeno número de pacientes estudados por doença, notou-se maior intensidade de imunoglobulinas e C3 nos pacientes com MCIC (Tabela 3).

A deposição de imunoglobulinas e porção C3 do complemento no interior dos vacúolos foi encontrada em poucos casos. Imunoglobulina A (IgA) foi encontrada em um caso de MCIC e em um caso de atrofia espinhal juvenil, IgG em um caso de MCIC e em um caso de miopatia distal, IgM em um caso de miopatia distal e C3 em um caso de MCIC. Em todos esses casos o depósito de imunoglobulinas ou complemento no interior dos vacúolos foi discreto.

\section{DISCUSSÃO}

O termo miosite com corpos de inclusão citoplasmática (MCIC) foi utilizado pela primeira vez por Yunis e Samaha em 1971 para descrever um caso semelhante a uma polimiosite crônica, cuja alteração marcante na biópsia muscular foi o achado de vacúolos dentro das fibras musculares e inclusões citoplasmáticas e nucleares ${ }^{15}$. Posteriormente foram relatados diversos casos de MCIC, incluindo duas séries com mais de 30 pacientes, o que permitiu a caracterização da doença como entidade clínica distinta ${ }^{16-20}$. A identificação de famílias com MCIC transmitida de forma autossômica dominante ou recessiva permitiu a subdivisão da MCIC nas formas hereditária e esporádica ${ }^{21,22}$. Existe grande heterogeneidade clínica e genética nas famílias com MCIC hereditária, mas de forma geral os pacientes apresentam início da doença mais precoce e não apresentam o infiltrado inflamatório abundante encontrado na forma esporádica ${ }^{23-25}$. Uma forma de MCIC autossômica recessiva encontrada em judeus iranianos que poupa o quadriceps teve o gene mapeado recentemente no cromossomo 9p1-q12.

A MCIC esporádica é considerada uma miopatia inflamatória idiopática que predomina em indivíduos do sexo masculino e geralmente apresenta início após os 50 anos de idade, evolução lenta e refratariedade ao tratamento. As enzimas séricas de origem muscular podem estar normais ou pouco aumentadas e a eletromiografia pode mostrar padrão miopático, neuropático ou misto ${ }^{1-}$ 3,18,20,27-29. O diagnóstico de MCIC fundamenta-se nas alterações encontradas na biópsia muscular. A característica principal é a presença de vacúolos marginados com forma irregular ou arredondada na microscopia óptica e inclusões filamentares nucleares e citoplasmáticas de diâmetro entre 10 e 21 $\mathrm{nm}$ na microscopia eletrônica ${ }^{16,18}$. Contudo, tanto os vacúolos marginados quanto as inclusões 
Tabela 3. Análise semi-quantitativa de macrófagos, células exterminadoras naturais, porção C3 do complemento e imunoglobulinas.

\begin{tabular}{|c|c|c|c|c|c|c|c|c|c|c|c|c|c|c|c|c|c|c|}
\hline \multirow[b]{2}{*}{ Caso } & \multicolumn{3}{|c|}{ Macrófago } & \multicolumn{3}{|c|}{ NK } & \multicolumn{3}{|c|}{$\mathrm{C} 3$} & \multicolumn{3}{|c|}{$\operatorname{IgA}$} & \multicolumn{3}{|c|}{$\operatorname{IgG}$} & \multicolumn{3}{|c|}{$\operatorname{IgM}$} \\
\hline & IT & IF & PV & IT & IF & PV & IT & IF & PV & IT & IF & PV & IT & IF & $\mathrm{PV}$ & IT & IF & PV \\
\hline 1 & ++ & + & + & + & 0 & 0 & 0 & 0 & 0 & 0 & 0 & 0 & 0 & 0 & 0 & 0 & 0 & 0 \\
\hline 2 & +++ & + & 0 & +++ & 0 & 0 & 0 & ++ & 0 & 0 & 0 & 0 & 0 & ++ & 0 & 0 & 0 & 0 \\
\hline 3 & +++ & + & + & +++ & 0 & 0 & 0 & + & 0 & ++ & ++ & 0 & 0 & + & 0 & 0 & + & 0 \\
\hline 4 & ++ & + & 0 & 0 & 0 & 0 & 0 & 0 & 0 & ++ & + & + & 0 & ++ & 0 & + & 0 & + \\
\hline 5 & + & 0 & 0 & + & 0 & 0 & 0 & 0 & 0 & 0 & 0 & 0 & 0 & 0 & + & + & 0 & + \\
\hline 6 & +++ & 0 & 0 & 0 & 0 & 0 & 0 & + & + & 0 & 0 & + & 0 & + & 0 & 0 & 0 & 0 \\
\hline 7 & +++ & 0 & 0 & 0 & 0 & 0 & 0 & 0 & 0 & 0 & 0 & 0 & 0 & 0 & 0 & + & 0 & 0 \\
\hline 8 & ++ & + & + & 0 & 0 & 0 & + & 0 & + & 0 & 0 & 0 & + & 0 & + & 0 & 0 & + \\
\hline 9 & 0 & 0 & 0 & 0 & 0 & 0 & 0 & 0 & 0 & + & + & + & 0 & 0 & 0 & + & 0 & + \\
\hline 10 & ++ & 0 & 0 & 0 & 0 & 0 & 0 & + & + & 0 & 0 & 0 & 0 & + & + & 0 & 0 & 0 \\
\hline 11 & + & + & + & 0 & 0 & 0 & 0 & 0 & + & ++ & 0 & 0 & + & ++ & + & 0 & 0 & + \\
\hline 12 & ++ & ++ & + & ++ & 0 & + & + & 0 & 0 & 0 & 0 & + & 0 & 0 & ++ & 0 & 0 & 0 \\
\hline 13 & +++ & 0 & + & + & 0 & 0 & 0 & 0 & 0 & 0 & 0 & 0 & 0 & 0 & 0 & 0 & 0 & 0 \\
\hline 14 & +++ & + & + & + & 0 & 0 & 0 & 0 & 0 & 0 & 0 & 0 & 0 & 0 & 0 & 0 & 0 & 0 \\
\hline 15 & +++ & 0 & 0 & 0 & 0 & 0 & 0 & 0 & + & 0 & 0 & 0 & 0 & 0 & 0 & 0 & + & 0 \\
\hline 16 & 0 & 0 & 0 & 0 & 0 & 0 & 0 & 0 & 0 & 0 & 0 & 0 & 0 & 0 & 0 & 0 & 0 & 0 \\
\hline
\end{tabular}

IT, interstício; IF, intra-fibra; PV, perivascular; NK, células exterminadoras naturais. 0 , ausente; + , discreto ou raro; ++, ocasional ou moderado; +++ , frequente ou abundante.

filamentares não são achados específicos, tendo sido descritos em diversas doenças neuromusculares $^{7,8}$. Vacúolos marginados já foram relatados em casos de miopatias distais ${ }^{6,30,31}$, distrofia oculofaringéia $^{32}$, polimiosite ${ }^{6}$, distrofia de cinturas pélvica e escapular ${ }^{4,6}$, miopatia congênita ${ }^{6}$, síndrome da espinha rígida ${ }^{7,33}$, atrofia muscular espinhal ${ }^{6}$ e em processos de desinervação $0^{7,34}$.

A patogênese da MCIC ainda não está elucidada. $\mathrm{O}$ acúmulo de prions, substâncias amilóide e de diversas proteínas características da doença de Alzheimer como beta-amilóide, tau hiper-

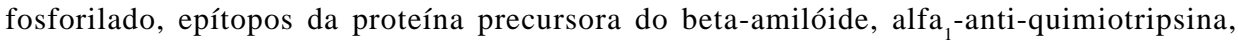
apolipoproteína E e ubiquitina nas fibras musculares da MCIC levantou a hipótese de que a doença possa ter caráter degenerativo $0^{23,35-39}$. Outros autores acreditam que pela maior frequência de fibras não-necróticas invadidas por linfócitos $\mathrm{T}$ em relação às fibras com depósito de amilóide, a

Tabela 4. Relação do número de células CD8+/CD4+.

\begin{tabular}{lccc}
\hline & \multicolumn{3}{c}{ Relação CD8+/CD4+ } \\
\cline { 2 - 4 } Doença & Interstício & Intra-fibra & Perivascular \\
\hline MCIC (n=4) & $3,9: 1$ & $7,1: 1$ & $19: 1$ \\
Atrofia espinhal juvenil $(\mathrm{n}=6)$ & $2: 1$ & $2,2: 1$ & $0: 0$ \\
Miopatia distal $(\mathrm{n}=3)$ & $1: 0$ & $1: 0$ & $1: 0$ \\
Distrofia de cinturas $(\mathrm{n}=2)$ & $2: 1$ & $1: 3,4$ & $7: 1$ \\
Neuropatia periférica $(\mathrm{n}=1)$ & $0: 0$ & $0: 0$ & $0: 0$ \\
\hline
\end{tabular}

MCIC, miosite com corpos de inclusão citoplasmática. 
citotoxicidade mediada por células T seja o fator mais importante na patogênese da $\mathrm{MCIC}^{40}$. Alterações mitocondriais tambem têm sido descritas na MCIC levantando a hipótese de que defeitos do metabolismo estejam envolvidos na patogênese da doença ${ }^{23}$. Aumento do número de mitocondrias foi relatado já na década de $70^{16}$ e fibras vermelho-rasgadas foram descritas mais tarde ${ }^{41}$. Deleções do DNA mitocondrial foram encontrados em $73 \%$ de 56 casos de MCIC da forma esporádica estudados através da reação em cadeia da polimerase e em $40 \%$ dos controles normais e $47 \%$ dos controles com outras doenças ${ }^{42}$.

Arahata e Engel foram os primeiros a estudar através de imunocitoquímica o infiltrado inflamatório na MCIC e em outras miopatias inflamatórias e encontraram predomínio de linfócitos $\mathrm{T}$ citotóxicos/supressores (CD8+) na MCIC, o que coincide como os nossos resultados ${ }^{9,10}$. Em contrapartida, Giorno e col. relataram predomínio de linfócitos CD4+ nas miopatias inflamatórias ${ }^{43}$. Em relação à localização, nos nossos casos o infiltrado foi predominantemente intersticial, ao invés da concentração endomisial (intra-fibra) relatada por outros estudos ${ }^{9,10}$. A presença de células CD4+ também foi maior no interstício que em torno das fibras musculares e espaços perivasculares. As células B foram raramente observadas no interstício e não foram vistas em torno de fibras musculares e espaço perivascular, o que está de acordo com a literatura ${ }^{9-11}$.

A demonstração de que a maioria dos linfócitos CD8+ na MCIC é do tipo citotóxico ao invés de supressor, levantou a hipótese de que a patogênese da doença esteja relacionada a agressão das fibras musculares por essas células ${ }^{11,44,45}$. Isso é reforçado pela expressão de antígenos do complexo de histocompatibilidade maior da classe I (MHC-I) no sarcolema das fibras musculares invadidas por linfócitos CD8+. Os antígenos do MHC-I não estão presentes em fibras musculares normais e são necessários para que ocorra a invasão de linfócitos $\mathrm{CD} 8+$ citotóxicos nas fibras não necróticas ${ }^{46}$.

Nas outras doenças foram observados índices de células inflamatórias menores que os encontrados MCIC, porém persistindo o predomínio de células CD8+. Nestas, encontramos poucas células B e na neuropatia periférica não foi encontrado qualquer tipo de célula. Procurando associar os casos de miopatias distais e de distrofia de cinturas pélvica e escapular com a distrofia muscular de Duchenne, verificamos que os achados são semelhantes, com a presença de maior número de células CD8+ em relação a CD4+, mas em número muito menor que nos casos de $\mathrm{MCIC}^{9,10}$. Estudos têm mostrado que biópsias musculares miopáticas ou neuropáticas podem conter pequeno número de linfócitos CD4+ e CD8+, com predomínio de linfócitos CD8+. Além disso, existem relatos da presença de células mononucleares ocasionais na biópsia muscular de pacientes sem doença neuromuscular, mas a importância desse achado ainda não foi determinada ${ }^{9,11,47}$.

Também foram encontradas em nossos casos grande proporção de macrófagos no interstício, fibra necrótica perivascular na MCIC, nas miopatias distais e em um dos casos de distrofia muscular de cinturas em todos os locais examinados. Nas atrofias espinhais e em outro caso de distrofia muscular de cinturas foram observados raros macrófagos no interstício, sendo que não foram observados na neuropatia periférica. Arahata e Engel também demonstraram que os macrófagos constituem elemento importante do infiltrado inflamatório da $\mathrm{MCIC}^{9,10}$. Os macrófagos são responsáveis pela fagocitose das fibras necróticas e talvez também tenham papel na patogênese da doença, já que são encontrados ao redor de fibras não necróticas, juntamente com linfócitos CD8+ ${ }^{9,11,47}$.

As células exterminadoras naturais $(\mathrm{NK})$ foram observadas no interstício da maioria dos casos de MCIC e mais raramente nos casos de atrofia espinhal, miopatias distais e distrofia de cinturas pélvica e escapular. As células NK apresentam citotoxicidade independentemente do complexo de histocompatibilidade tipo I (MHC-I) e sua participação na patogênese da MCIC ainda é desconhecida, já que essas células constituem pequena porcentagem do total de células inflamatórias ${ }^{9,11,48}$. Foram descritos dois pacientes com MCIC associada à imunodeficiência variável comum em que havia grande porcentagem de células NK invadindo fibras musculares que não expressavam antígenos do MHC-I, sugerindo a participação dessas células no processo de lesão muscular desses $\operatorname{casos}^{48}$. 
A relação de células CD8+/CD4+ foi maior na região perivascular e em torno de fibras necróticas que no interstício das fibras, nos casos de MCIC. Nas demais entidades patológicas, a relação de células CD8+/CD4+ foi menor que na MCIC. Exceto pelos trabalhos de Engel e Arahata, que encontraram padrão semelhante na $\mathrm{MCIC}^{9,10}$, raros trabalhos aparecem na literatura. Assim, não foi possível melhor avaliação ${ }^{19}$.

No presente estudo, como estamos estudando todos os casos que apresentavam corpos de inclusão, procuramos também verificar se existia um mecanismo humoral comum aos diversos tipos de doenças. Tivemos dificuldades na diferenciação quantitativa e qualitativa da deposição de complemento e imunoglobulinas, nos diferentes tipos de doenças que determinam a produção de corpos de inclusão citoplasmática. Este resultado vem ao encontro de outros estudos em doenças neuromusculares e em doenças do colágeno com envolvimento muscular, em que as alterações encontradas pelos diversos autores são consideradas inespecíficas, podendo ocorrer em casos de lesões das fibras musculares de diversas etiologias ${ }^{49,50}$. A simples deposição, ou a presença desses complexos imunes, não é suficiente para determinar a lesão podendo não ter relação com os achados anatomopatológicos ${ }^{49,51-53}$.

Este estudo sugere que a presença de infiltrado inflamatório importante auxilia na diferenciação da MCIC esporádica de outras doenças neuromusculares que apresentam vacúolos marginados. $\mathrm{Na}$ MCIC ocorre grande concentração de linfócitos CD8+ e a relação CD8+/CD4+ é maior que nas outras doenças neuromusculares aqui estudadas. Isso é importante porque na maioria das vezes os exames laboratoriais e neurofisiológicos não diferenciam a MCIC das outras doenças com corpos de inclusão citoplasmática ${ }^{8}$. Além disso, o maior número de linfócitos CD8+ no interstício nas MCIC do que nas outras doenças sugere uma reação citotóxica mediada pelo complexo de histocompatibilidade maior (MHC-I). Nas outras doenças com corpos de inclusão citoplasmática aqui estudadas, o processo imunológico provavelmente é secundário à lesão muscular.

\section{REFERÊNCIAS}

1. Calabrese LH, Chou SM. Inclusion body myositis. Rheum Dis Clin North Am 1994;20:955-972.

2. Dalakas MC. Polymyositis, dermatomyositis and inclusion-body myositis. N Engl J Med 1991;325:1487-1498.

3. Dalakas MC. Immunopathogenesis of inflammatory myopathies. Ann Neurol 1995;37(Suppl 1):S74-S86.

4. Chutkow JC, Heffner Jr RR, Kramer AA, Edwards JA. Adult-onset autosomal dominant limb-girdle muscular dystrophy. Ann Neurol 1986;20:240-248

5. Engel AG, Banker BQ (eds). Ultrastructural changes in diseased muscle. In Engel AG, Franzini-Armstrong C. Myology: basic and clinical. New York: McGraw-Hill, 1994:889-1017.

6. Fukuhara N, Kumamoto T, Tsubaki T. Rimmed vacuoles. Acta Neuropathol 1980;51:229-235.

7. Jongen PJH, Ter Laak HJ, Stadhouders AM. Rimmed basophilic vacuoles and filamentous inclusions in neuromuscular disorders. Neuromusc Disord 1995;5:31-38.

8. Scola RH, Werneck LC, Franco CRC. Corpos de inclusão citoplasmática: estudo em diversas doenças e revisão da literatura. Arq Neuropsiquiatr 1996;54:245-259.

9. Arahata K, Engel AG. Monoclonal antibody analysis of mononuclear cells in myopathies: I. Quantitation of subsets according to diagnosis and sites of accumulation and demonstration and counts of muscle fibers invaded by T cells. Ann Neurol 1984;16:193-208.

10. Engel AG, Arahata K. Monoclonal analysis of mononuclear cells in myopathies: II. Phenotypes of autoinvasive cells in polymyositis and inclusion body myositis. Ann Neurol 1984;16:209-215.

11. Engel AG, Arahata K. Mononuclear cells in myopathies: quantitation of functionally distinct subsets, recognition of antigenspecific cell-mediated cytotoxicity in some diseases, and implications for the pathogenesis of the different inflammatory myopathies. Hum Pathol 1986;17:704-721.

12. Figarella-Branger D, Pellissier JF, Pouget J, et al. Myosites à inclusions et maladies neuromusculaires avec vacuoles bordées. Rev Neurol (Paris) 1992; 148:281-290.

13. Werneck LC. O valor da biópsia muscular em neurologia. Rev Bras Clin Terap 1981;10(Suppl):2-20.

14. Werneck LC. Estudo da biópsia muscular e sua relação com enzimas séricas e eletromiografias nas doenças musculares. Tese (Professor Titular), Universidade Federal do Paraná. Curitiba, 1991.

15. Yunis EJ, Samaha FJ. Inclusion body myositis. Lab Invest 1971;25:240-248.

16. Carpenter S, Karpati G, Heller I, Eisen A. Inclusion body myositis: a distinct variety of idiopathic inflammatory myopathy. Neurology 1978;28:8-17.

17. Eisen A, Berry K, Gibson G. Inclusion body myositis: myopathy or neuropathy? Neurology 1983;33:1109-1114.

18. Lotz BP, Engel AG, Nishino H, Stevens JC, Litchy WJ. Inclusion body myositis: observations in 40 patients. Brain 1989;112:727-747. 
19. Ringel SP, Kenny CE, Neville HE, Giorno R, Carry MR. Spectrum of inclusion body myositis. Arch Neurol 1987;44:1154-1157.

20. Sayers ME, Chou SM, Calabrese LH. Inclusion body myositis: analysis of 32 cases. J Rheumatol 1992;19:1385-1389.

21. Askanas V, Engel WK, Alvarez RB. Enhanced detection of Congo-red-positive amyloid deposits in muscle fibers of inclusion body myositis and brain of Alzheimer disease using fluorescence technique. Neurology 1993;42:1265-1267.

22. Neville HE, Baumbach LL, Ringel SP, Russo LS Jr, Sujansky E, Garcia CA. Familial inclusion body myositis: evidence for autosomal dominant inheritance. Neurology 1992;42:897-902.

23. Griggs RC, Askanas V, DiMauro S, et al. Inclusion body myositis and myopathies. Ann Neurol 1995;38:705-713.

24. Andreu OM, Fernández-Solá J, Clotet EP, et al. Miositis con cuerpos de inclusión: presentación familiar de tres casos. Rev Clin Esp 1994;194:974-977.

25. Simmons Z, Towfighi J, Reichwein RK, Kothari J. Hereditary inclusion body myopathy resembling spinal muscular atrophy. Neurology 1997;48(Suppl 2):A124-A125.

26. Argov Z, Tiram E, Eisenberg I, et al. Various types of hereditary inclusion body myopathies map to chromosome 9p1-q1. Ann Neurol 1997;41:548-551.

27. Hopkinson ND, Hunt C, Powell RJ, Lowe J. Inclusion body myositis: an underdiagnosed condition? Ann Rheum Dis 1993;52:147-151.

28. Lindberg C, Persson LI, Björkander J, Oldfors A. Inclusion body myositis: clinical, morphological, physiological and laboratory findings in 18 cases. Acta Neurol Scand 1994;89:123-131.

29. Luciano CA, Fujii M, Koffman B, Dalakas MC. Histologic correlates of fibrillation potentials in inclusion body myositis. Neurology 1997;48(Suppl 2):A125.

30. Ikeuchi T, Asaka T, Saito M, et al. Gene locus for autosomal recessive distal myopathy with rimmed vacuoles maps to chromosome 9. Ann Neurol 1997;41:432-437.

31. Nonaka I, Sunohara N, Ishiura S, Satoyoshi E. Familial distal myopathy with rimmed vacuole and lamellar (myeloid) body formation. J Neurol Sci 1981;51:141-155.

32. Coquet M, Vital C, Julien J. Presence of inclusion body myositis-like filaments in oculopharyngeal muscular dystrophy: ultrastructural study of 10 cases. Neuropathol Appl Neurobiol 1990;16:393-400.

33. Van Munster ETL, Joosten EMG, van Munster-Uijtdehaage MAM, Kruls HJA, ter Laak HJ. The rigid spine syndrome. J Neurol Neurosurg Psychiatry 1986;49:1292-1297.

34. Abarbanel JM, Lichtenfeld Y, Zirkin H, et al. Inclusion body myositis in post-poliomyelitis muscular atrophy. Acta Neurol Scand 1988;78:81-84.

35. Askanas V, Engel WK, Mirabella M. Idiopathic inflammatory myopathies: inclusion body myositis, polymyositis, and dermatomyositis. Curr Opin Neurol 1994;7:448-456.

36. Mendell JR, Sahenk Z, Gates T, Paul L. Amyloid filaments in inclusion body myositis; novel findings provide insight into nature of filaments. Arch Neurol 1991;48:1229-1234.

37. Mirabella M, Alvarez RB, Engel WK, Weisgraber KH, Askanas V. Apolipoprotein E and apolipoprotein RNA in muscle of inclusion body myositis and myopathies. Ann Neurol 1996;40:864-872.

38. Sarkozi E, Askanas V, Johnson SA, Engel WK, Alvarez RB. Beta-amyloid precursor protein mRNA is increased in inclusion body myositis. Neuroreport 1993;4:815-818.

39. Sarkozi E, Askanas V, Engel WK. Abnormal accumulation of prion protein mRNA in muscle fibers of patients with sporadic inclusion-body myositis and hereditary inclusion-body myositis. Am J Pathol 1994;145:1280-1284.

40. Pruitt JN, Showalter CJ, Engel AG. Sporadic inclusion body myositis: counts of different types of abnormal fibers. Ann Neurol 1996;39:139-143.

41. Sekul EA, Dalakas MC. Inclusion body myositis: new concepts. Semin Neurol 1993;13:256-263.

42. Santorelli FM, Sciacco M, Tanji K, et al. Multipe mitochondrial DNA deletions in sporadic inclusion body myositis: a study of 56 patients. Ann Neurol 1996;39:789-795.

43. Giorno R, Barden MT, Kohler PF, Ringel S. Immunohistochemical characterization of mononuclear cells infiltrating muscle of patients with inflammatory and noninflammatory myopathies. Clin Immunol Immunopathol 1984;30:405-412.

44. Arahata K, Engel AG. Monoclonal antibody analysis of mononuclear cells in myopathies: IV. Cell-mediated cytotoxicity and muscle fiber necrosis. Ann Neurol 1988;23:168-173.

45. Arahata K, Engel AG. Monoclonal antibody analysis of mononuclear cells in myopathies: V. Identification and quantitation of T8+ cytotoxic and T8+ supressor cells. Ann Neurol 1988;23:493-499.

46. Emslie-Smith AM, Arahata K, Engel AG. Major histocompatibility complex class I antigen expression, immunolocalization of interferon subtipes, and T cell-mediated cytotoxicity in myopathies. Hum Pathol 1989;20:224-231.

47. Lemoine NR, Ryan JF, Cox EL, Mayston V, Revell PA, Swash M. Immunohistochemical analysis of mononuclear cell susets in inflammatory and non-inflammatory myopathies. J Clin Pathol 1986;39:271-274.

48. Dalakas MC, Illa I. Common variable immunodeficiency and inclusion body myositis: a distinct myopathy mediated by natural killer cells. Ann Neurol 1995;37:806-810.

49. Isenberg DA. Immunoglobulin deposition in skeletal muscle in primary muscle disease. Q J Med 1983;207:297-310.

50. Rodrigues CJ, Carvalho MS, Levy JA. Imunofluorescência direta em músculo esquelético de pacientes com doenças neuromusculares. Rev Bras Neurol 1988;24:147-150.

51. Mastaglia FL, Ojeda VJ. Inflammatory myopathies. Ann Neurol 1985;17:215-227.

52. Oxenhandler R, Adelnstein EH, Hart MN. Immunopathology of skeletal muscle: the value of direct immunofluorescence in the diagnosis of conective tissue disease. Hum Pathol 1977;8:321-328.

53. Whitaker JN, Engel WK. Vascular deposits of immunoglobulin and complement in idiopathic inflammatory myopathy. $\mathrm{N}$ Engl J Med 1972;286:333-338. 